\title{
Toward the Future of Personal Computing System Construction
}

\author{
Yoshiki Ohshima
}

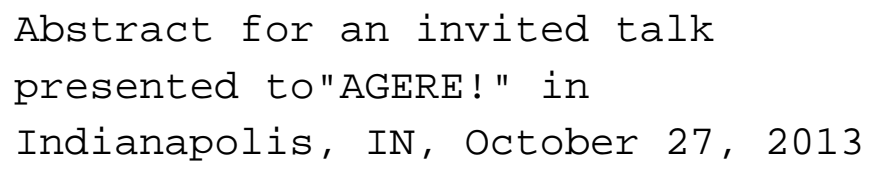

VPRI Memo M-2013-004 


\title{
Toward the Future of Personal Computing System Construction
}

\author{
Yoshiki Ohshima \\ Viewpoints Research Institute \\ yoshiki@vpri.org
}

\section{Abstract}

The software for today's personal computing environments has become so complex that no single person can understand an entire system. Our group's early experiences with personal computing led us to understand that the essential model of personal computing can be expressed much more compactly. Our group engaged in a project (called the STEPS project) to materialize that vision over the last six years [1].

Several interesting results came out of the STEPS project. There are various meta-language implementations [2][3]. A new stream-processing language called Nile was invented. The syntax of Nile allows a fully-featured vector graphics engine called Gezira to be written in a clean, mathematical manner in less than 500 lines of code [4]. We also wrote a dynamic, yet declarative, graphical user interface framework in which we built a universal document editor [5].

From the experience with the STEPS project, we are exploring the next steps; one of the directions is to incorporate the idea of using multiple constraint solvers to build a system. Solvers can help stronger "negotiation" between objects and languages, and help the system to be written in a more declarative manner. Another direction is to take the idea of loose-coupling to the next level; objects should not know about other objects directly but should always negotiate and "find" other objects.

As the basic concept for this next stage, we are using the "Internet all the way down" analogy. The Internet has proven itself to be a great engineering feat: it scaled from just four nodes to billions of nodes without ever needing a full shutdown for maintenance. It is also likely that we can take out a random $10 \%$ of the Internet's nodes and it will still keep running. By building a personal computing

Permission to make digital or hard copies of part or all of this work for personal or classroom use is granted without fee provided that copies are not made or distributed for profit or commercial advantage and that copies bear this notice and the full citation on the first page. Copyrights for third-party components of this work must be honored. For all other uses, contact the owner/author(s).

AGERE! '13, October 27, 2013, Indianapolis, Indiana, USA.

Copyright is held by the owner/author(s).

ACM 978-1-4503-2602-5/13/10.

http://dx.doi.org/10.1145/2541329.2541346 environment that consists of such nodes, or objects, perhaps we can make it never need to be restarted.

Interestingly, J. C. R. Licklider already foresaw the need for program components to discover each other on a huge network of computers. From that viewpoint, what we are trying to do is to carry the vision forward.

Categories and Subject Descriptors D.3.3 [Language Constructs and Features]: Frameworks

Keywords Exploratory Programming; The Internet All the Way Down Model

\section{Short Bio}

Yoshiki Ohshima is a researcher at Viewpoints Research Institute. He worked on the Etoys environment for children via the "XO" and the One Laptop Per Child (OLPC) initiative. He holds a MSc and $\mathrm{PhD}$ from Tokyo Institute of Technology on software transactions and a massively parallel particle progamming system. At Walt Disney Imagineering $\mathrm{R} \& \mathrm{D}$, he worked on theme park related research projects as well as end-user computer environments.

\section{References}

[1] Alan Kay, Dan Ingalls, Yoshiki Ohshima, Ian Piumarta, and Andreas Raab. Steps Toward the Reinvention of Programming. Technical report, Viewpoints Research Institute, 2006. Proposal to NSF; Granted on August 31st 2006.

[2] Alessandro Warth and Ian Piumarta. OMeta: an object-oriented language for pattern matching. In Proceedings of the 2007 symposium on Dynamic languages, DLS '07, pages 11-19, New York, NY, USA, 2007. ACM.

[3] Ian Piumarta. Accessible Language-Based Environments of Recursive Theories (a white paper advocating widespread unreasonable behavior). Technical report, Viewpoints Research Institute, 2005. VPRI Research Note RN-2006-001-a.

[4] Dan Amelang. Gezira. https://github.com/damelang/ gezira.

[5] Yoshiki Ohshima, Aran Lunzer, Bert Freudenberg, and Ted Kaehler. KScript and KSWorld: A Time-aware and Mostly Declarative Language and Interactive GUI Framework. In Proceedings of the 2013 ACM International Symposium on New Ideas, New Paradigms, and Reflections on Software, Onward! '13, pages 117-134, New York, NY, USA, 2013. ACM. 